\title{
Research Paper \\ The Role of Rumination and Psychological Hardiness in Predicting High Risk Behaviors in Students
}

Azam Rahbarian $^{* 1}$, Hamed Salehi², Majid Gharibdoust ${ }^{3}$, Hossein Mahmoudi ${ }^{4}$

1. M.A. Student of General Psychology, Shahrekord Branch, Islamic Azad University, Shahrekord, Iran

2. M.A. in Preschool Education, Faculty of Psychology and Educational Sciences, Allameh Tabataba'i University, Tehran, Iran

3. M.A. in Positive Islamic Psychology, Tehran Branch, Islamic Azad University, Tehran, Iran

4. M.A. in Educational Psychology, Faculty of Psychology and Educational Sciences, Ferdowsi University of Mashhad, Iran

Citation: Rahbarian A, Salehi H, Gharibdoust M, Mahmoudi H. The role of rumination and psychological hardiness in predicting high risk behaviors in students. Quarterly Journal of Child Mental Health. 2020; 7(2): 31-40.

\section{http://dx.doi.org/10.29252/jemh.7.2.4}

\section{A R T I C L E I N F O}

\section{Keywords:}

Rumination, psychological hardiness, high-risk behaviors

Received: 19 Mar 2020 Accepted: 20 Jun 2020 Available: 9 Sep 2020

\section{A B S T R A C T}

Background and Purpose: Whereas high-risk behaviors result in serious individual and social damages, identifying these behaviors and factors influencing them is highly important. In this regard, during the recent years, thinking patterns of the way these behaviors shape and persist has been investigated by the psychologists and clinicians. Therefore, the present study was conducted to investigate the role of rumination and psychological hardiness in predicting high-risk behaviors of adolescents.

Method: The present research was a descriptive correlational study. The study population included all the male students studying at the first cycle of secondary school at Sarayan city in the academic year of 2019-2020, among which 205 students were selected as the sample group through convenience sampling. Ruminative Responses Scale (Nolen-Hoeksema\& Morrow, 1991), Psychological Hardiness Questionnaire (Kiamarie et al., 1998) and Risky Behavior Questionnaire (Mohammadi et al., 2011) were used to gather the required data. Data were analyzed by the statistical methods of mean, standard deviation, Pearson correlation coefficient, and simultaneous multiple regression.

Results: Results showed that there was a significant positive relationship between rumination and high-risk behaviors $(\mathrm{P}<0.001)$, while psychological hardiness and its components had a significant negative relationship with high-risk behaviors ( $\mathrm{P}<0.001)$. Additionally, rumination and psychological hardiness explained $26.6 \%$ of adolescent high-risk behaviors variance $(\mathrm{P}<0.01)$. Conclusion: Based on the results of this research, it can be concluded that reducing the subjective interpretations and modifying the psychological indicators like resilience can reduce the adolescent risky behaviors.

\footnotetext{
* Corresponding author: Azam Rahbarian, M.A. Student in General Psychology, Shahrekord Branch, Islamic Azad University, Shahrekord, Iran. E-mail addresses: Aezamrahbarian@gmail.com
}

2476-5740/ (C) 2019 The Authors. This is an open access article under the CC BY-NC-ND license (https://creativecommons.org/licenses/by-nc-nd/3.0/). 


\section{نقش نشخوار فكرى و سرسختى روانشناختى در بيشينى خطريذيرى دانش آموزان}

\section{اعظم رهبريان"'، حامد صالحى"، مجيد غريب دوست"، حسين محمودى}

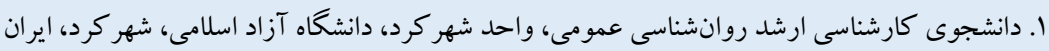

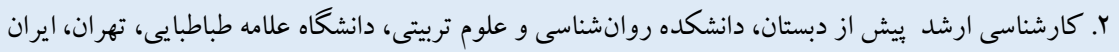

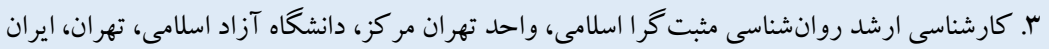

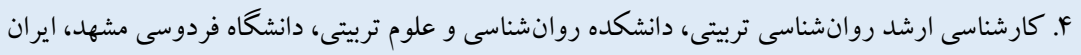

\section{جكيده}

زمينه و هدف: با توجه به اينكه انجام رفتارهاى برخطر باعث ايجاد آسيبهاى جدى به فرد و جامعه مىشود، شناسايى اين گونه رفتارها و

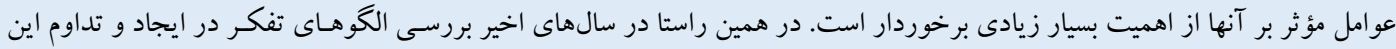

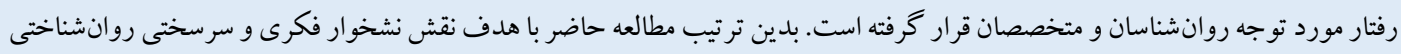
در يِيشبينى خطريذ يرى نوجو انان انجام شد.

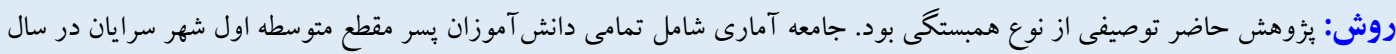

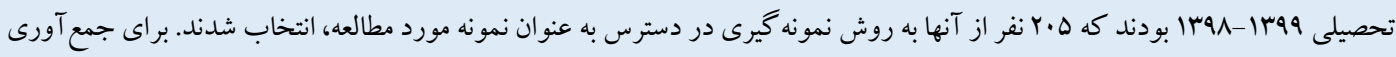

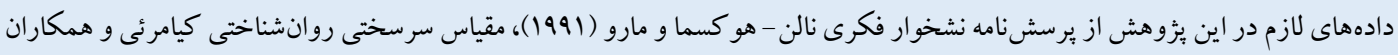
(ITVW)

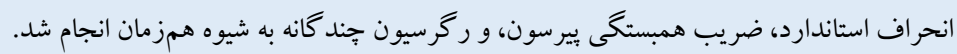

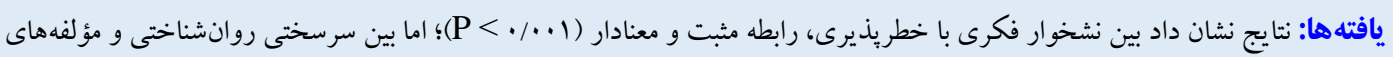

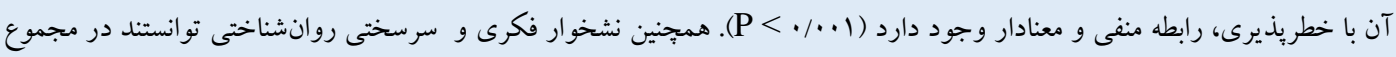

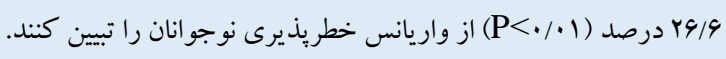

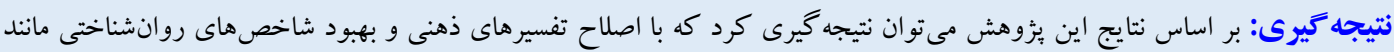

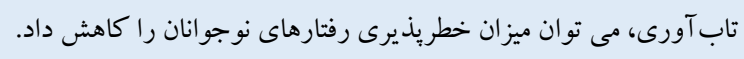

مشخصات مقاله

كليدوازهها:

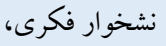

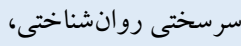

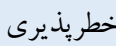

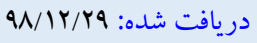

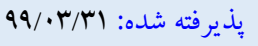

منتشر شده: 99/19 (9)

* نويسنده مسئول: اعظم رهبر يان، دانشجوى كارشناسى ارشد روانشناسى عمومى، واحد شهر كرد، دانشكاه آزاد اسلامى، شهر كرد، ايران.

راياناهه: Aezamrahbarian@gmail.com

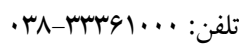


هيجـــانى و بررســى افكـار ناخواسـته و نقـشـ آن در دوام اختلالات

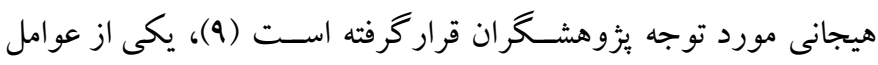

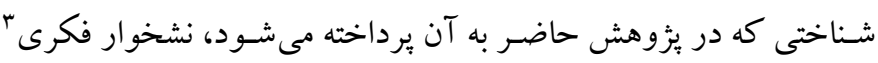

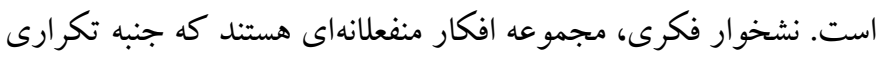
دارند، بر علل و نتايج علائم متمر كزند، و مانع حل مسئله سازشيافته شده

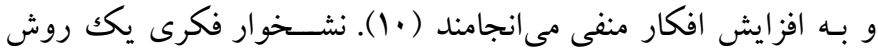
تنظيم شـناختى هيجانى نابهنجار اسـت كه افراد در ياسـخ به تجربه يكك

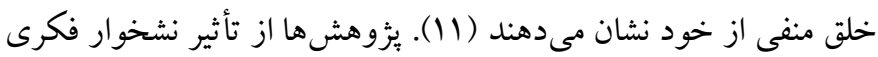

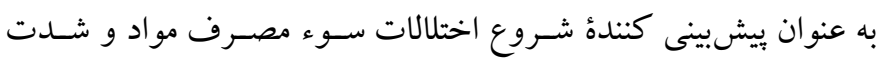

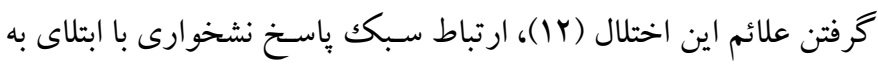

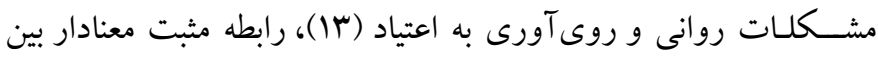

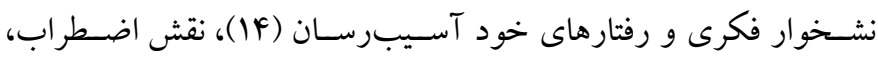
غفلت، مشكلات در روابط با همسالان، قلدرى و نشخوار فكرى بر اعتياد يذيرى (10)، رابطه انواع نشخوار با مصرف مو اد در سنين نوجوانى (19)،

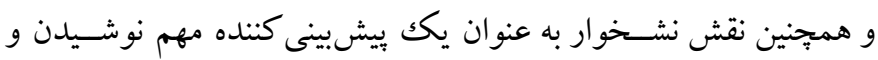

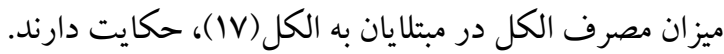

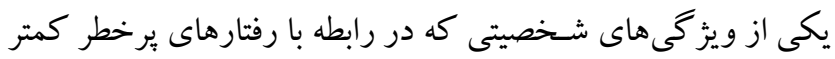

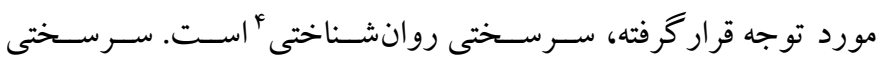

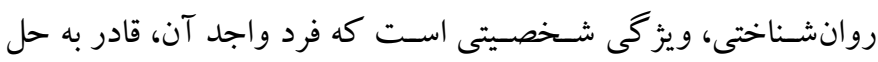

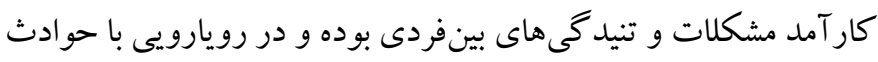
از آن به عنوان منبع مقاومت و همانند سبرى محافظ استفاده مى كند (1) (1).

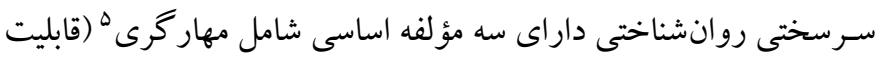

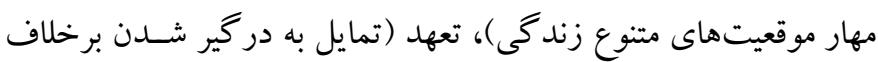

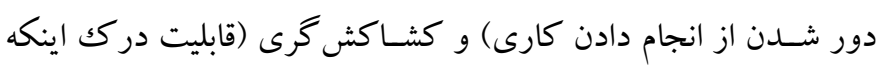

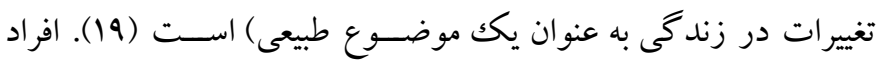

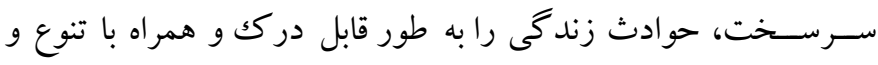

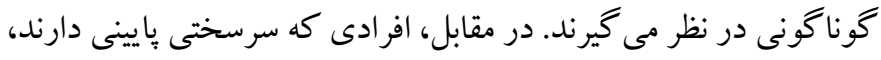

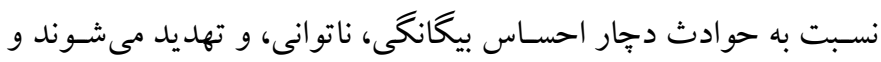

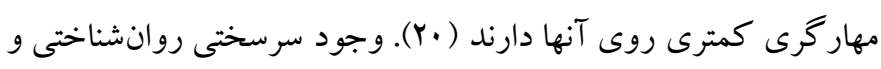

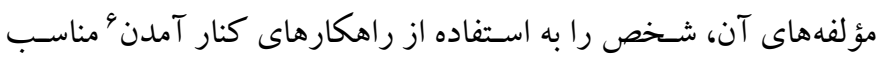

4. Psychological hardiness

5. Control

6. Coping
مقلدمه

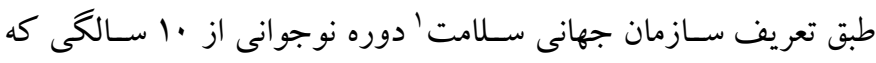

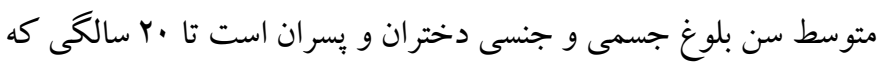

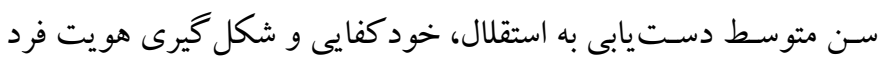

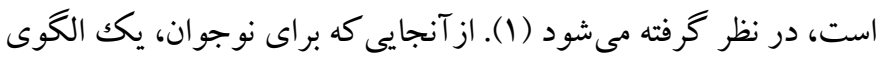

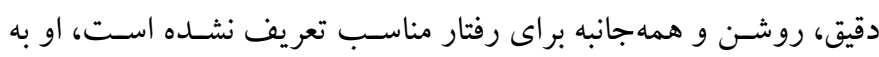

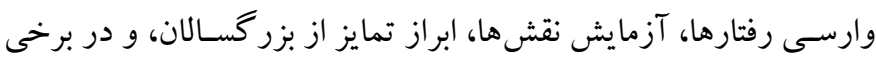

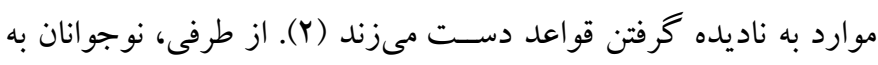

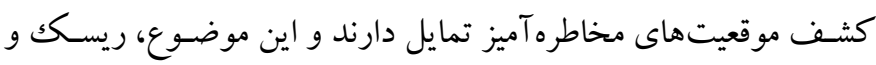

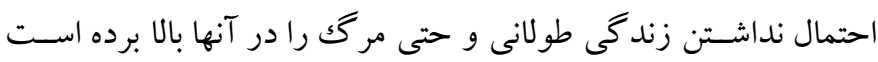

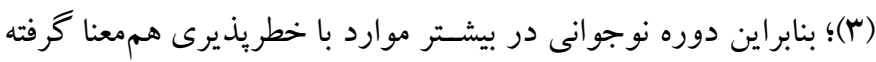

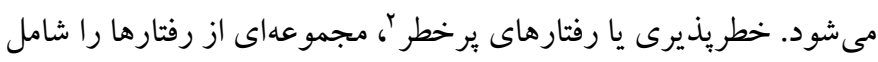

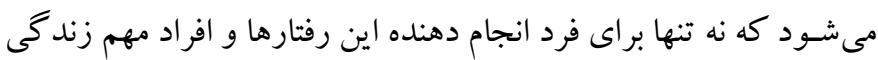

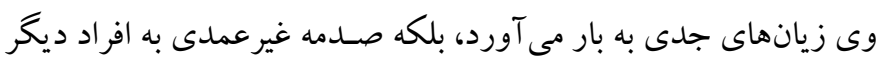

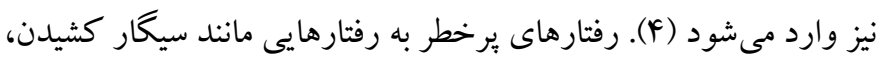

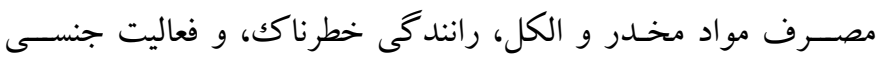

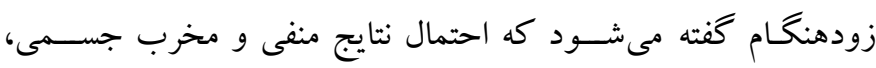

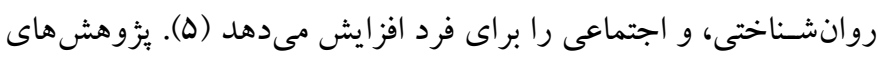

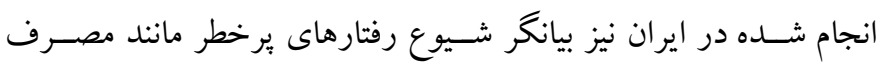

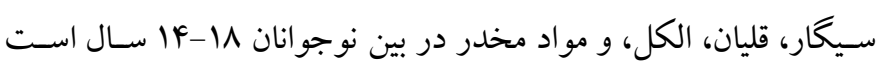

امروزه علل مختلفى براى گرايش به رفتارهاى برخطر گزارش شـده

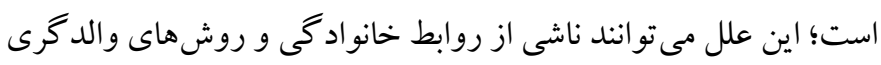

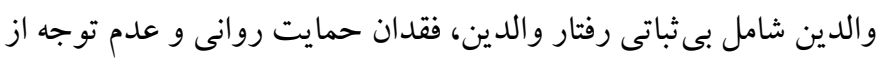

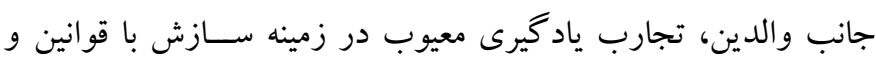

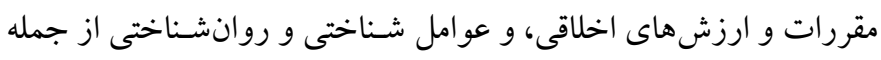

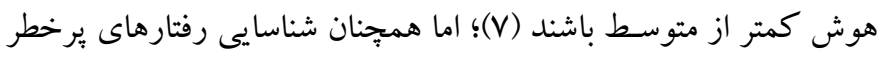

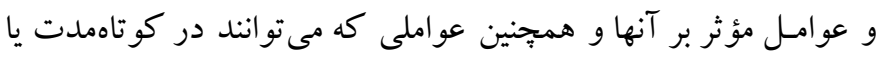

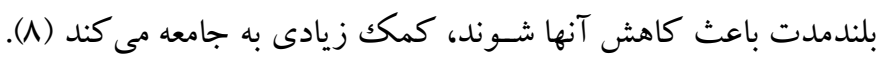

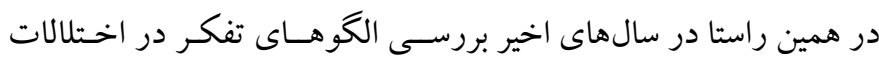

1. World health organization

2. High-risk behaviors

3. Rumination 
نشخوار فكرى و سرسختى روانشناختى مىتواند خطريذيرى نوجو انان را

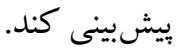

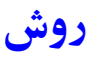

الف) طرح ئوهش و شـــ كت كنند كان: يزوهش حاضـر توصسيفى از

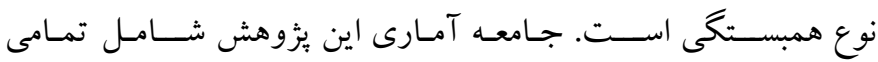

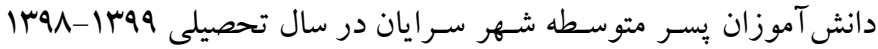

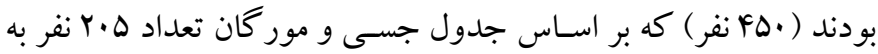
روش نمونه گيرى در دسـترس از بايههاى مختلف تحصـيلى و موقعيت هاى جغر افيايى متفاوت، انتخاب شـدند. بدين ترتيب از بين مدارس شهر

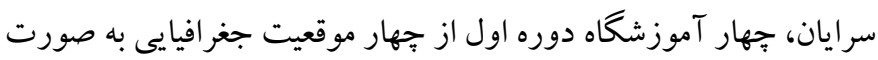
در دسترس انتخاب شـدند و افراد نمونه بر حسب شرايط ورود و خروج از مطالعه به صــورت در دسـترس مورد مطالعه قرار گرفتند. ملاككهاى

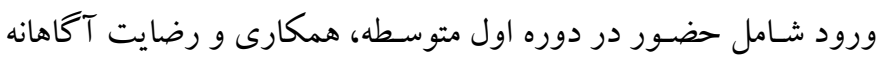
براى شـركت در بزوهش، و داشــن سـلامت روانى بر اســاس برونده مشاورهاى موجود در مدرسه بود. همجنين ملاككهاى خروج افراد نمونه

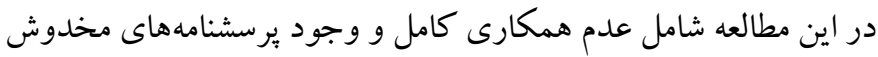

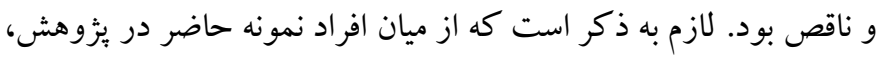

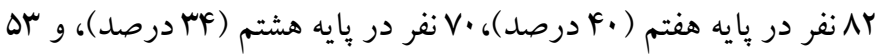

$$
\text { بفر در بايه نهم (4) دورصد) بودند. }
$$

1. مقياس نشخوار فكرى'! اين مقياس توسط نولن - هو كسـما و مترو در

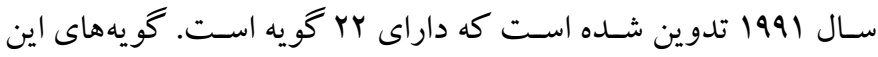
مقياس بر اسـاس طيف ليكرت جهار گزينهاى از هركز (1) تا هميشه (F)

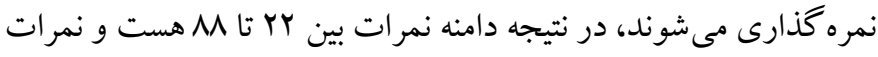

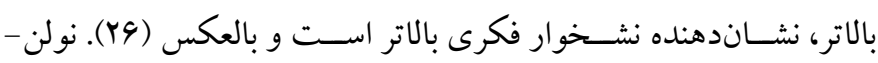
ها كسـما و مارو، روايى محتوايى اين مقياس را مطلوب ارزيابى كردند و

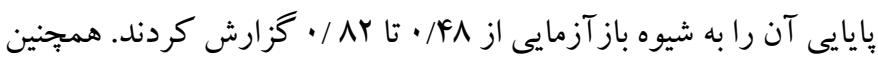
ضريب اعتبار آن را به روش آلفاى كرونباخ •9/ • به دست آرودند (צ'). در ايران نيز لطفىنيـا و همكاران روايى اين مقياس را تأييد و ضسريب رونس

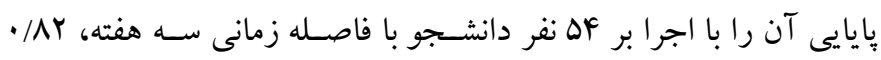

كه منجر به حل مسئله خواهد شد، سوق مىدهد. اين افر اد با رويدادهاى زندگى به جاى استفاده از راهكارهاى كنار آمدن وإيسرونده مانند انكار

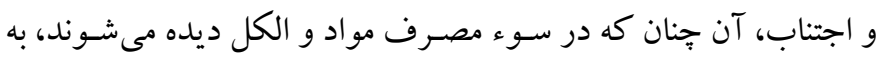
رويارويى مستقيم با آنها مى يردازند (Y) (Y). در همين راستا مطالعه جوبيجيان

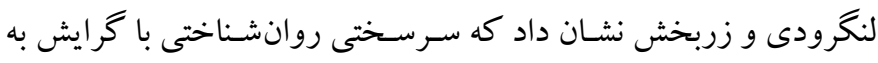
اعتياد، رابطه معنادار دارد (Yr). در مطالعهاى ديخر نشــان داده شـــ كه روته

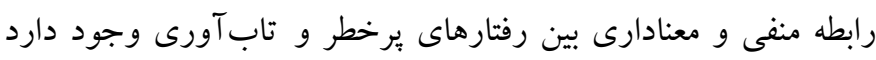

بررسـى رفتارهاى برخطر در نوجوانى از نظر ييامدهايى كه براى

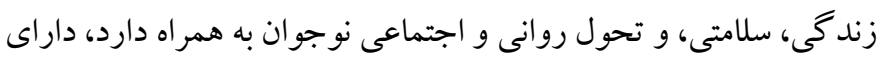

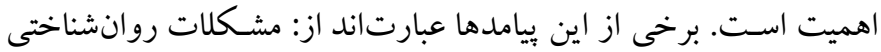
مانند افسردگى، مرگك زودرس، ايدز و بيمارىهاى جنسى، انخيزه بايين

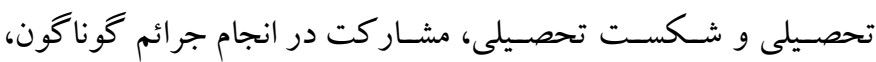
مصرف مواد مخدر، خشونت، و رفتارهاى جنسى. اين رفتارهاى برخطر،

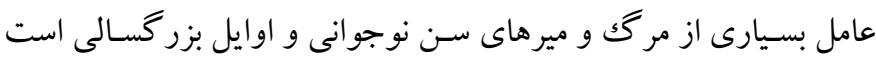
(YY)

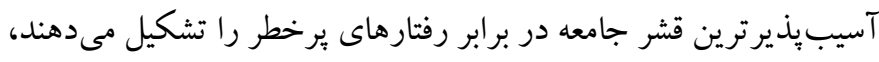

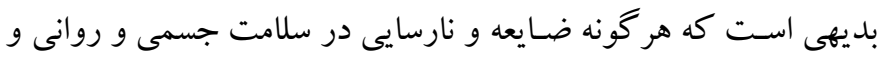

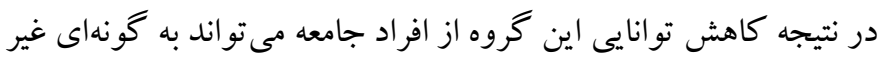

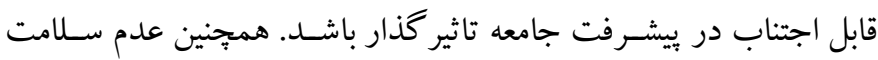

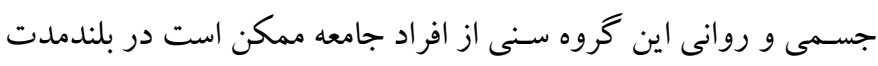

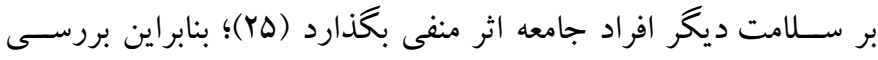

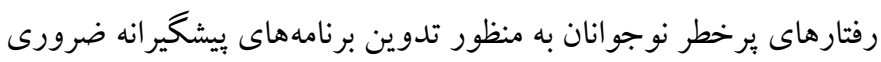
اسـت. در اين ارتباط با توجه به اهميت رفتارهاى يرخطر در نوجوانان، بررسى عوامل مؤثر در آن، و محدود بودن مطالعات انجام شــــه درباره

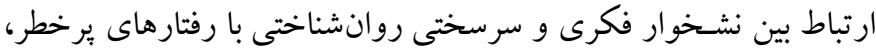
خلأ يزووهشى در اين حيطه در كشورمان احساس مى شود. در نتيجه مطالعه

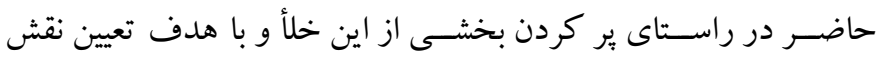

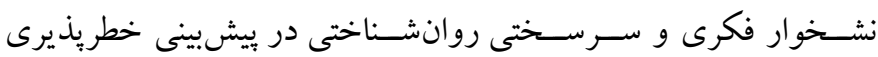
نوجو انان انجام شـد؛ و به دنبال بِاسـخ به اين سؤوال است كه تا جه اندازه

1. Rumination scale 


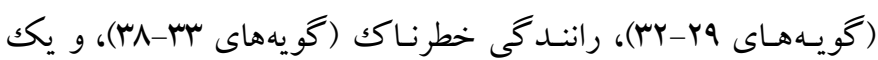

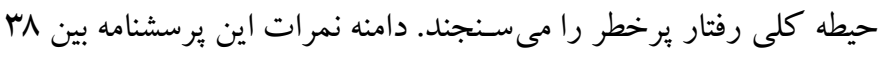

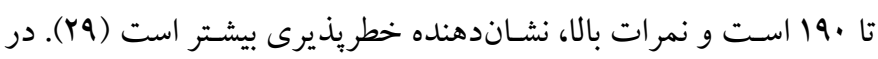

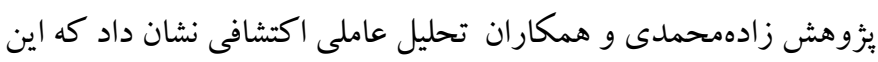

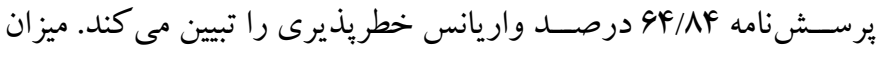

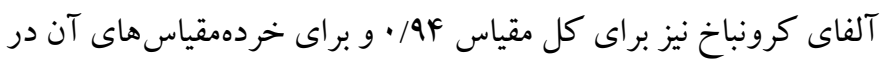

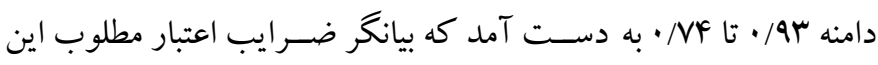

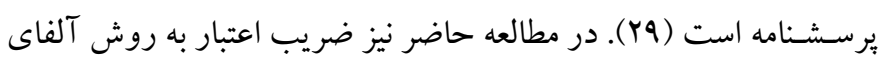

$$
\text { كرونباخ وه/ • به دست آمد. }
$$

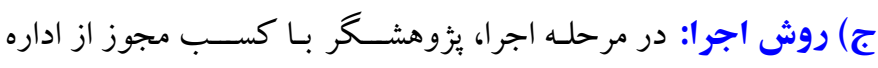

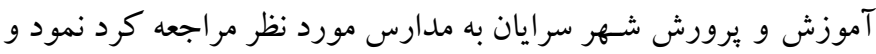

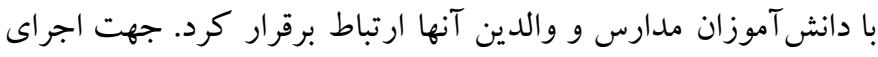
اين مطالعه از كادر ادارى و آموزشى مدارس نيز مجوز مهاى للازم اخذ شد.

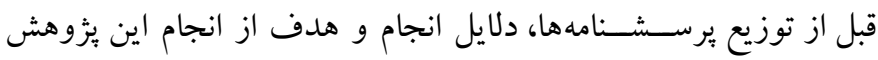

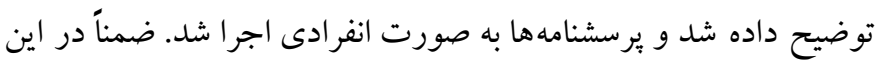
يُزوهش تمامى اصول اخلاقى مرتبط با قوانين انجمن روانشناسى آمريكا

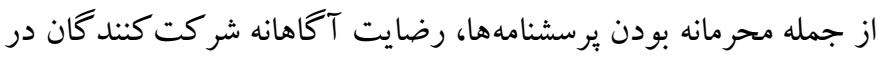

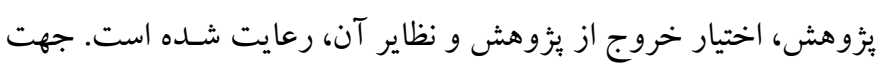

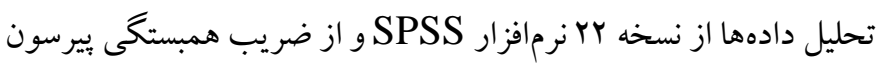
و آزمون رگرسيون جند كانه به شيوه همزمان ادمان استفاده شد.

يافته ها

در جـدول ا، شــاخص هاى توصـيفى متغيرهاى يزوهش مانند انحر اف

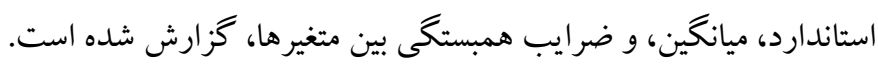

محاسـبه كردهاند (YV). در مطالعه حاضـر نيز ضـريب اعتبار اين مقياس با استفاده از روش آلفاى كرونباخ، ז^/ • به دست آمد.

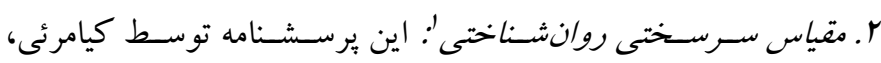

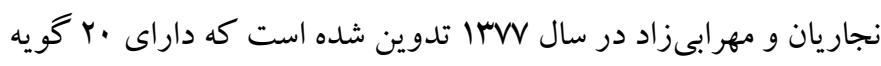

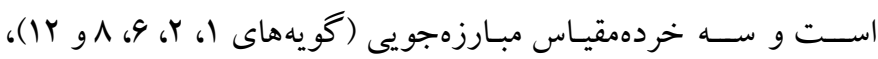

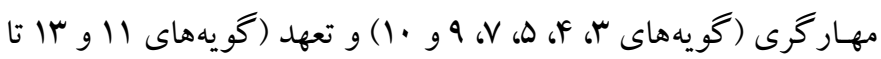

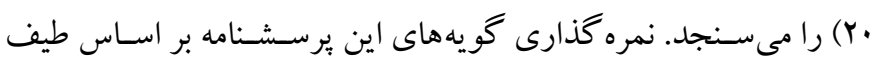

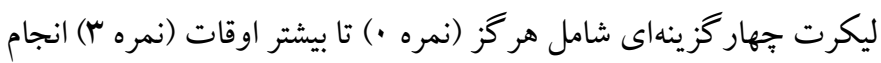

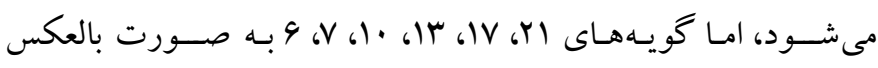

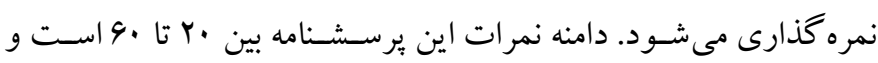

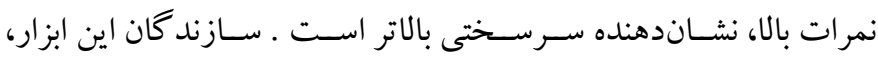
ضــرايب اعتبار آن را به دو روش باز آزمايى و آلفاى كرونباخ به ترتيب

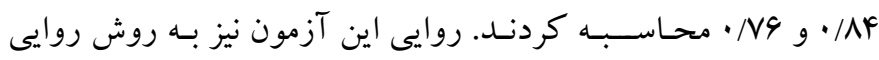

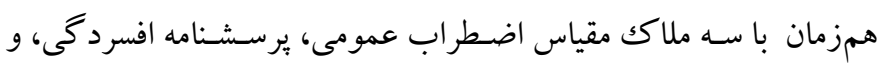

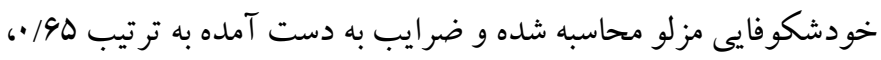

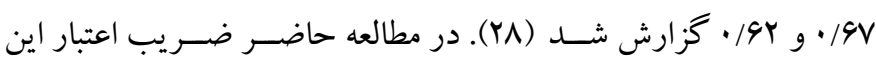
آزمون به روش آلفاى كرونباخ N9/ • به دست آمد.

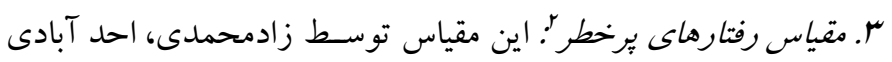

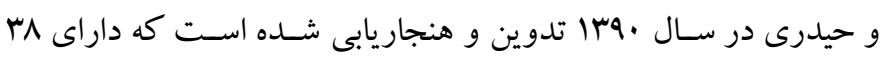

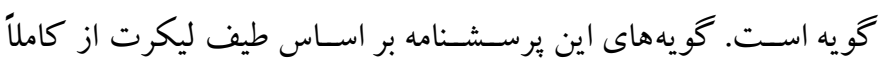

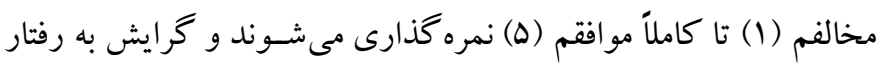

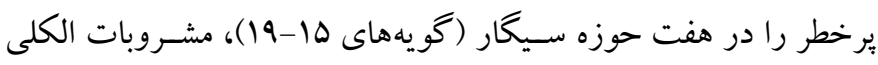
(كويههاى (YY-Y.

جدول ا: انحراف استاندارد، ميانكين، و ضرايب همبستكى بين متغير هاى يزوهش

\begin{tabular}{|c|c|c|c|c|c|c|c|c|}
\hline خطر يذيرى & سرسختى & تعهل & مهار & مبارزهجويى & نشخوار & ميانتين & انحراف استاندارد & متغير ها \\
\hline & & & & & 1 & $N / F F$ & $F Y / \Delta q$ & نشخوار فكرى \\
\hline & & & & 1 & $-\cdot / r 19^{* *}$ & $r / 1$ & $9 / 11$ & مبارزهجويى \\
\hline & & & 1 & $-\cdot / \Delta r V^{* *}$ & $-\cdot / r V V^{* *}$ & r/Or & $11 / r V$ & مهارگرى \\
\hline & & 1 & $-\cdot / \mu \cdot v^{\star \star}$ & $-\cdot /$ YYq $^{* \star}$ & $-\cdot / \Gamma_{Y} \cdot{ }^{* *}$ & $r / \mu \wedge$ & $I V / F A$ & تعهد \\
\hline & 1 & $-.19 V r^{* *}$ & $-\cdot / \Delta 9 Y^{* *}$ & $-\cdot 19 \cdot 9^{* *}$ & $-\cdot / \mu \wedge r^{* *}$ & $V / 91$ & $\mathrm{rV} / \mathrm{AV}$ & سرسختى \\
\hline 1 & $-\cdot / \Delta \wedge r^{* *}$ & $-\cdot /\left.\Delta V\right|^{* *}$ & $-\cdot / F \wedge \Delta^{* *}$ & $-\cdot / 011^{* *}$ & $\cdot|\Delta V|^{* *}$ & $\mid r / T 9$ & SF/TD & خطريذيرى \\
\hline
\end{tabular}


براى بيشبينى خطريـــيرى نوجوانـان بر اســاس نشــخوار فكرى و

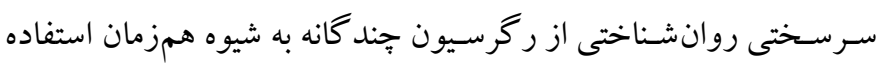
شد كه خلاصه نتايج آن در جدول ب گزارش شده است.
بر اسـاس دادههاى جدول ا، ضريب همبستخى بين نشخوار فكرى با خطريذيرى، مثبت و معنادار ( (DVI •) و ضسريب همبستخى بين سرسختى

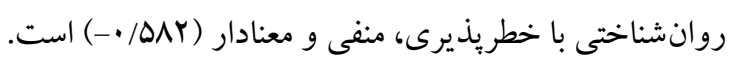

جدول r: خلاصه نتايج مدل بيشبينى خطريذيرى نوجوانان از روى نشخوار فكرى و سرسختى روانشناختى

\section{خطاى استاندارد بر آورد}

rr/IIIf

(Rمديل

- rFa
واريانس تبيين شده

•/Y94
همبستكى جندكانه (R)

.1019
جدول آ، نتايج تحليل واريانس مدل براى بررسى توانايى بيشبينى متغير

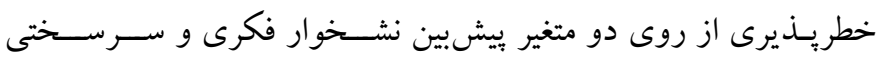
روانشناختى گزارش شده است.

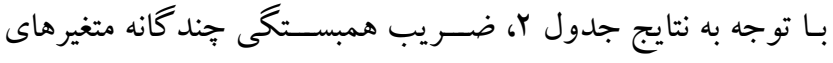
نشـوار فكرى و سـرسـتى روانشـناختى با خطر يذيرى، همجينين دو متغير نشـخوار فكرى و سـرسـتى روانشـناختى در مجموع

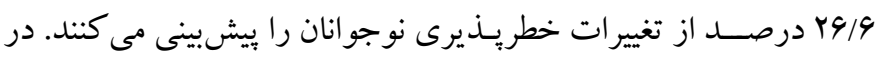

جدول r: نتايج آزمون تحليل واريانس ركرسيون جند متغيرى

\begin{tabular}{|c|c|c|c|c|c|}
\hline سطح معنادارى & $\mathbf{F}$ & ميانكين مجذورات & درجه آزادى & مجموع مجذورات & مدل \\
\hline \multirow[t]{3}{*}{.$/ \cdot 1$} & $4 / / \Delta 9 \Delta$ & rrr./NIr & F & QTYT/YSOY & رگرسيون \\
\hline & & $\Delta 9 / . \mathrm{HQ}$ & $r \cdot$. & $11 Y \cdot V / 19 \mathrm{~V}$ & باقيمانده \\
\hline & & & $r \cdot F$ & $r \cdot \Delta r \cdot / F r$. & كل \\
\hline
\end{tabular}

ييشبينى متغير ملاكك يعنى خطريذيرى را دارند. در جدول f) ضــــايب استانداردشده و استاندارد نشده رگرسيون گزارش شده است.

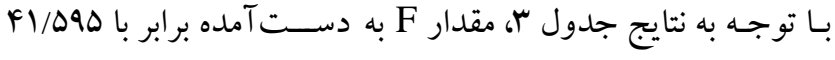
هست كه در سطح 1 • • معنادار است؛ بنابراين مىتوان نتيجه گرفت كه متغير هاى بيشبين (نشـخوار فكرى و سـرسـتى روانشـناختى)، تو انايى

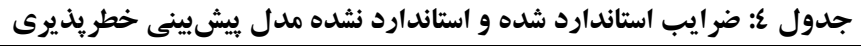

\begin{tabular}{|c|c|c|c|c|c|}
\hline \multirow[t]{2}{*}{ سطح معنادارى (P) } & \multirow[t]{2}{*}{$\mathbf{t}$} & \multirow{2}{*}{ ضرايب استانداردشده } & \multicolumn{2}{|c|}{ ضرايب استاندارد نشده } & \\
\hline & & & خطاى استاندارد & B & \\
\hline.$/ .1$ & $\Lambda / \wedge \Delta I$ & - & $F / F \cdot \Delta$ & rN/৭91 & ثابت \\
\hline$\cdot / \cdot \cdot 1$ & $r / 991$ & - /rYa & $\cdot / \mathrm{IV}$ & •/vaV & نشخوار فكرى \\
\hline.$/ .1$ & $-9 / r \cdot 1$ & $-\cdot / r V I$ & $\cdot / M A V$ & $-1 / 109$ & تعهد \\
\hline$\cdot / \cdot \cdot 1$ & $-F / r r$. & $-\cdot / r \Delta r$ & $\cdot / 1 \wedge 9$ & $-\cdot /$ vq & مبارزهجويى \\
\hline.$/ .1$ & $-r / r V I$ & $-\cdot / \Lambda$. &.$/ 194$ & $-\cdot \cdot \Delta r r$ & مهارگرى \\
\hline
\end{tabular}


اسـت (IV). بدين ترتيب نتايج مطالعات ذكر شــده در راسـتا و همسـو با نتايج يثزوهش حاضر است. در تبين يافته فوق مىتوان كفت كه نشخوار فكرى از طريق ناخوشى هيجـانى، تلخى، نفرت، خصــومـت، خشـــم و ترس بر كرايش به اعتياد دانش آموزان تأثير كذار است. نشخوار فكرى اثرات خلق منفى را برجسته مسى كـــد و در نستيجـه تمركز و عملكرد فرد مختـل مىشــود (11). دانش آموزانى كه در آنها يس از وقوع اشـتباه، نشخوارهاى فكرى نمايان مىشـــود؛ آشــفتخى هاى بين فردى وخيم تر بوده و بر كســترش تر كيب يبيجيدهاى از احسـاسات منفى نسبت به كسى كه به آنها صدمه زده است، منجر مى شود. اين قبيل نشخوارهاى فكرى به طور بيوسته تكرار مىشوند و احسـاسـات منفى كه همراه كننده رفتارهاى يرخطر هستند را بررنگكتر مى كنند. در واقع نشـــوار فكرى افكار منفعلانه، ناخواســـه، و تكرارى هستند (Y) كه مانع حل مسئله به طور سازش يافته شده و به افزايش افكار منفى منتهى مىشـود كه اين نيز به نوبه خود بر ناكار آمدى مسائل عاطفى منجر مى شــود. نتيجـه اينكـه نشــخوار فكرى موجسب مى شــود كـهـ دانش آموزان در بيان مسائل و عواطف خود محدود شوند و تمايل آنها به خطر يذيرى و انجام رفتارهاى بر خطر، افزايش يابد. در تبينى ديخر مى توان كفت وقتى فـــد در نـشخوار فكـــى غـرق مىشـود، احسـاس مى كند كه دجار وضـعيت غير قابل مهارى شـده كه خطرناكك است؛ يعنى باورهاى منفى در مورد نشخوار فكــــى به وجود مى آيد و منجر به افسرده شــدن فرد مىشـود و اين مســله بر اخـــتلالات هيجــانى و دوام اختلالات هيجانى، اثر گذار هست (11)، نشخوار فكرى جنانجه كُته شد به عنوان اشتغال دائمى به يكك انديشه يا موضوع و تفكر درباره آن شـناخته مىشود كه بر علل و نتايج علائم متمركز هست و مانع حل مســـله ســازشيافته شـــده و در نتيجه به افزايش افكار منفى منجر مىشـود ( • ). اين وضسعيت در نهايت ممكن است به ايجاد خلق افسرده در فرد ختم شــود و در نتيجـه گرايش به انجام رفتارهاى برخطر در فرد

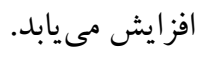
ديخر يافته اين يثزوهش نشـان داد كه بين سـرسـختى روانشسناختى با خطريذيرى، ارتباط منفى و معنادارى وجود دارد و همجينين سـرسـختى روانشــاختى و ابعاد آن (تعهد، مهارگرى، و مبارزهجويى) به صـورت منفى، خطريـــيرى را بيشبينى مى كنتـد. از اين يـافتـه مىتوان اين كونه
با توجه به نتايج جدول F، اثر نشخوار فكرى بر خطريذيرى (qץ//•)

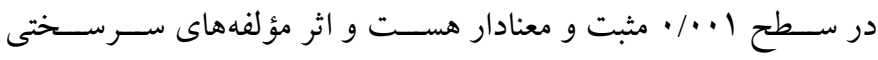

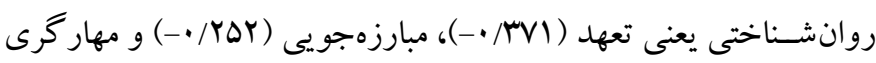

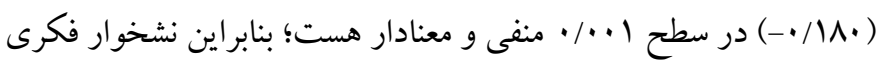

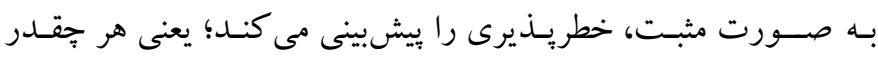
نوجوانان بيشتر دجار نشخوار فكرى شوند، خطريذيرى بيشترى را تجربه مى كنند. همجينين مؤلفه هاى سرسختى نيز خطر يذيرى را به صورت منفى

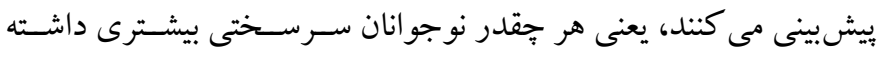
باشد، خطريذيرى كمترى دارند.

\section{بحث و نتيجه تيرى}

يزٔوهش حاضر با هلف نقش نشخوار فكرى و سرسختى روانشناختى در بيشبينى خطريذيرى نو جوانان انجام شـد. نتايج نشان داد كه بين نشخوار فكرى بـا خطريسـيرى رابطـه مثبـت و معنـادارى وجود دارد. همجينين نشخوار فكرى به صورت مثبت، خطريذيرى را بيشبينى مى كند. از اين يـافته مى توان اين كونه برداشـت كرد كه افراد داراى نمرات بالاتر در نشخوار فكرى، خطريذيرى بيشترى دارند و بالعكس. نتيجه به دست آمده با نتايج مطالعات بيشين در اين زمينه همسو است؛ به عنوان مثال در مطالعه نالن - هو كســما تأثير نشــخوار فكرى به عنوان بيشبينى كننده شــروع اختلالات سـوء مصسرف مواد و شدت گرفتن علائم اين اختلال، تأييد شد (Y) (I). آبلا و همكاران معتقدند افر ادى كه در مواجهه با مشـكلات زندكى و ازجمله تنيدكى از سـبك يُاسـخ نشـخوارى اسـتفاده مى كنند، مسـتعد ابتلاى به مشـكلات روانى و روى آورى به اعتياد هسـتند (سا). مطالعه خدمتى نيز نشـان داد كه بين نشخوار فكرى و رفتارهاى خودآسيبرسان رابطه مثبـت معنادارى وجود دارد و نشــخوار فكرى به طور مثبت و معنادارى رفتارهاى خود آسـيبرسان را ييشبينى مى كند (| (|). در همين رابطه بزوهش جمنى و سـجاديان (هان) نشـان داد كه اضـطراب، غفلت، مشكلات در روابط با همسالان، قلدرى، و نشخوار فكرى بر اعتياديذيرى تأثير معنادارى دارند. همجنين در بثزوهشى، ويلم و همكاران دريافتند كه انواع نشـخوار در مصسرف مواد در سـن نوجوانيف نقش معنادارى دارد (19). بالاخره نتايج يزوهش براو و همكاران نشـان داد كه نشـخوار، يكك ييشبينى كننده مهم نوشـيدن و ميزان مصـرف الكل در مبتلايان به الكل 
در مجموع بايد گفت نتايج اين مطالعه مى تواند در كنار يافتهاى

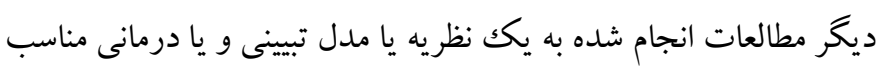

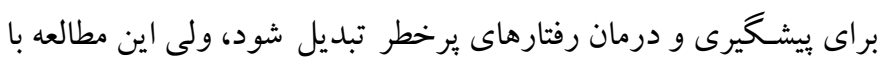

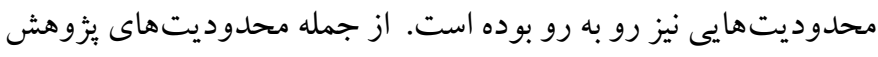

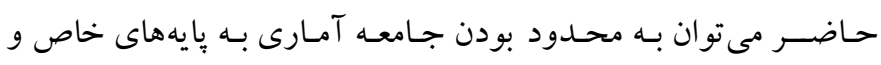

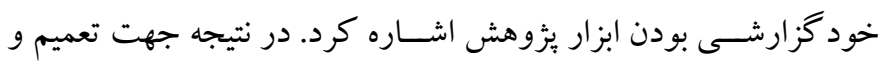

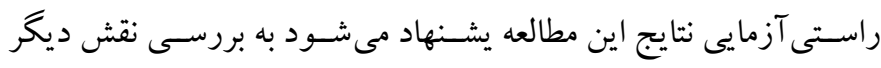

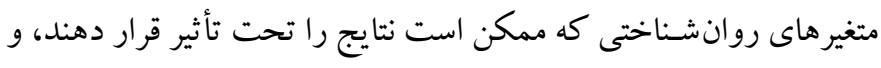

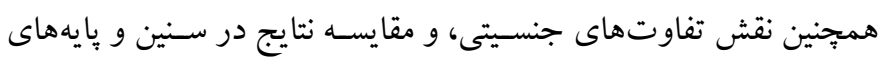
تحصسيلى مختلف در مطالعات بعدى توجه شـود. بر اسـاس يافتهاى اين

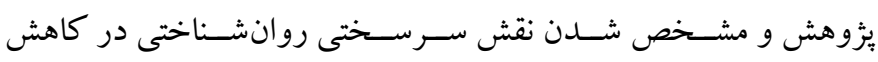
رفتارهاى يرخطر، بيشـنهاد مى شود كه به آموزش مؤلفه هاى اين سازه در

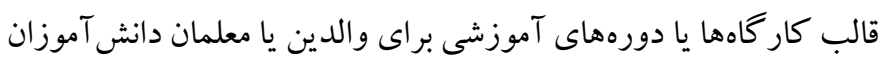

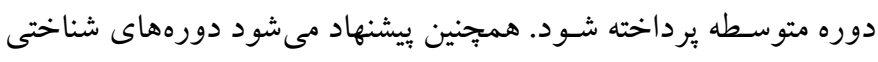

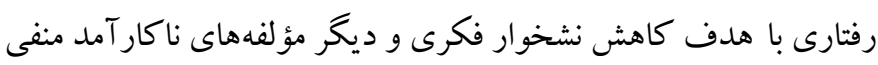
براى نوجوانان بر ززار شود.

تشـكر و قدردانى: اين مطالعه به صـورت مسـتقل اجرا شــده اسـت و مجوز

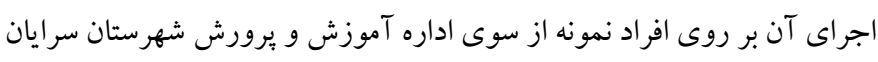

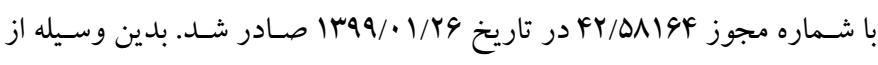

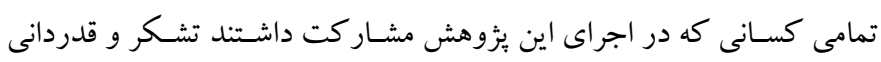

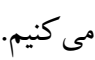
تضــاد منــافع: نو يســــــان اعلام مى دارند كه هيج گونه تضــاد منافعى بين نويسند كان وجود ندارد.
اسـتنباط كرد كه هر جه سـرسـتى روانشـناختى نوجو انان بيشـتر باشـد،

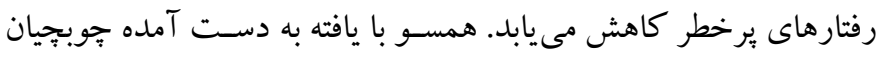

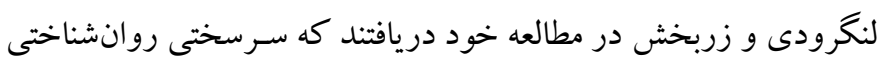

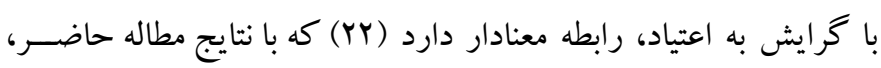

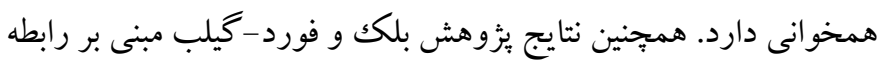

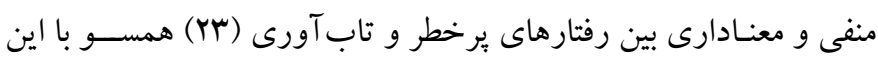
ئزوهش است. در تبيين يافته فوق مىتوان كفت كه وجود سـرستخى روانشناختى، فرد را به اسـتفاده از راهكارهاى مقابلهاى تبديلى كه منجر به حلى حل مســئله

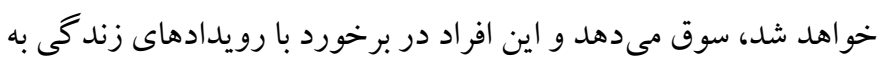

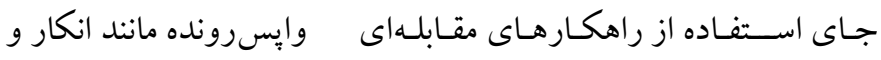

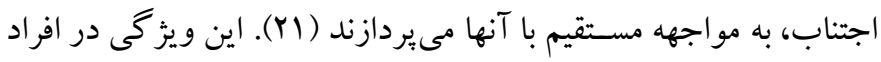

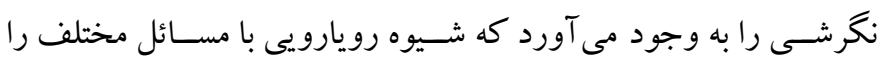

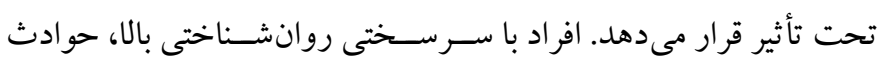

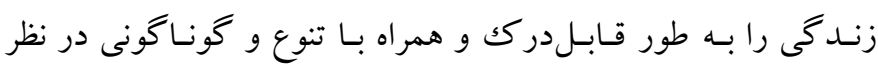

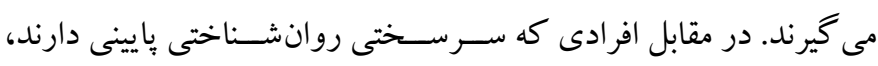

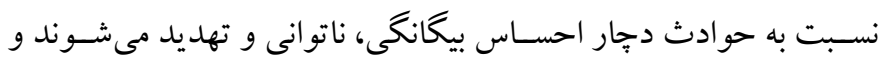

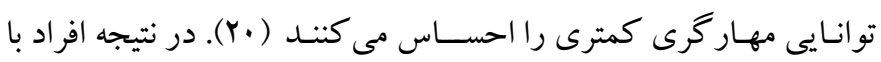
سرسختى روانشناختى بالا، كمتر به رفتارهاى برخطر روى مي مى آورند.

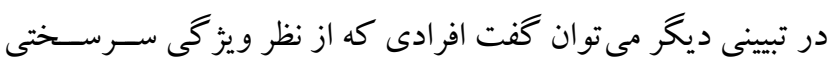

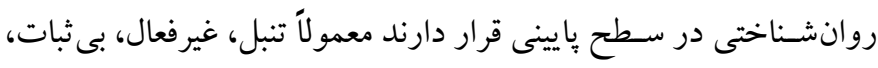

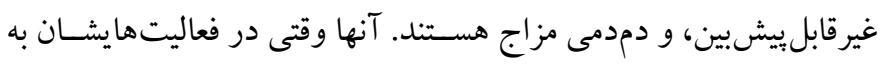

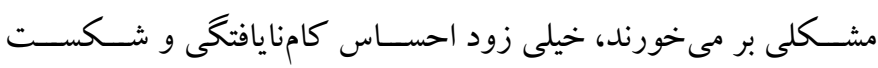

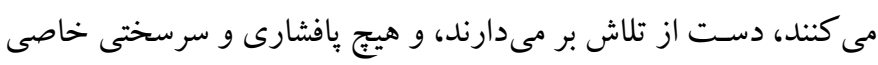

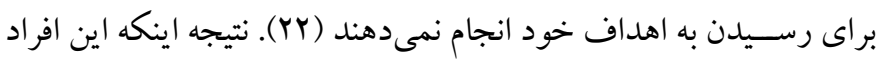

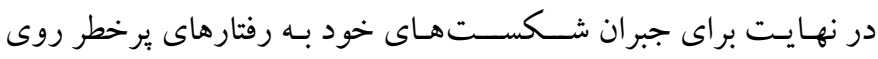

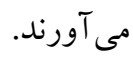




\section{Reference}

1. Organization WH. Adolescent health and development in nursing and midwifery education. New York: World Health Organization; 2004. [Link]

2. Mousavi SV, Pasandideh Z, Poorabolghasem Hosseini S. The effectiveness of emotional intelligence training on risk taking of adolescent girls. JPEN. 2017; 4(2):1-8. [Persian]. [Link]

3. Krcmar M, Greene K. Connections between violent television exposure and adolescent risk taking. Media Psychology. 2000; 2(3):195-217. [Link]

4. Campbell JA, Walker RJ, Egede LE. Associations between adverse childhood experiences, high-risk behaviors, and morbidity in adulthood. Am J Prev Med. 2016; 50(3):344-352. [Link]

5. Hertz MF, Everett Jones S, Barrios L, David-Ferdon C, Holt M. Association between bullying victimization and health risk behaviors among high school students in the united states. IJSH. 2015; 85(12):833-842. [Link]

6. Marzban A. Prevalence of high risk behaviors in high school students of Qom, 2016. JMJ. 2018; 16(3):4451. [Persian]. [Link]

7. Prado G, Pantin H, Huang S, Cordova D, Tapia MI, Velazquez MR, et al. Effects of a family intervention in reducing HIV risk behaviors among high-risk Hispanic adolescents: A randomized controlled trial. PAM. 2012; 166(2):127-133. [Link]

8. Habibi Kaleybar R, Shaban Basim F, Samimi Z, Mollamohseni M, Azizi S. Explaining high-risk behaviors among students on the basis of religious orientation and spiritual health. Islamic Life Style. 2018; 2(4):203-209. [Persian]. [Link]

9. Rahbaran R, Karami R, Shahmohammadi M. The effectiveness of behavioral activation therapy on rhubarb and depression disorders in adolescents. Thoughts and Behavior in Clinical Psychology. 2019; 14(52):17-26. [Persian]. [Link]

10. Rod K. observing the effects of mindfulness-based meditation on anxiety and depression in chronic pain patients. Psychiatr Danub. 2015; 27(1):209-211. [Link]

11. Schut DM, Boelen PA. The relative importance of rumination, experiential avoidance and mindfulness as predictors of depressive symptoms. ACBS. 2017; 6(1):8-12. [Link]

12. Nolen-Hoeksema S, Stice E, Wade E, Bohon C. Reciprocal relations between rumination and bulimic, substance abuse, and depressive symptoms in female adolescents. Journal of abnormal psychology. 2007; 116(1):198-207. [Link]

13. Abela JR, Skitch SA, Auerbach RP, Adams P. The impact of parental borderline personality disorder on vulnerability to depression in children of affectively ill parents. J. Pers. Disord. 2005; 19(1):68-83. [Link]

14. Khedmati $\mathrm{N}$. The relationship between rumination and difficulty of emotion regulation with self-harm behaviors in students. Rooyesh-e-Ravanshenasi. 2020; 8(11):19-26. [Persian]. [Link]

15. Chamani N, Sajjadian I. The causal relationship between anxiety, rumination, neglect, peer relationship and bullying with the readiness of addiction. Research on Addiction. 2019; 13(51):219240. [Persian]. [Link]

16. Willem L, Bijttebier P, Claes L, Raes F. Rumination subtypes in relation to problematic substance use in adolescence. Pers Individ Dif. 2011; 50(5):695-699. [Link]

17. Bravo AJ, Pilatti A, Pearson MR, Mezquita L, Ibáñez MI, Ortet G. Depressive symptoms, ruminative thinking, drinking motives, and alcohol outcomes: A multiple mediation model among college students in three countries. Addictive behaviors. 2018; 76:319327. [Link]

18. Bartone PT, Valdes JJ, Sandvik A. Psychological hardiness predicts cardiovascular health. Psychology, health \& medicine. 2016; 21(6):743-749. [Link]

19. Saxena S. Relationship between psychological hardiness and mental health among college students. IJHW. 2015; 6(8):12-19. [Link]

20. Zeer EF, Yugova EA, Karpova NP, Trubetskaya OV. Psychological predictors of human hardiness formation. IJESE. 2016; 11(14):7035-7044. [Link]

21. Molazadeh E, Rahim, Kafy M, Salehy E. The comparison of hardiness and coping styles with psychological stress in addicted and normal people. Research on Addiction. 2011; 5(17):41-57. [Persian]. [Link]

22. Choubchian Langarudi H, Zarbakhsh PD, M.R. The relationship between psychological hardiness, coping styles, emotion regulation, and tendency toward addiction among students. QJFR. 2018; 15(3):31-50. [Persian]. [Link]

23. Black C, Ford-Gilboe M. Adolescent mothers: resilience, family health work and health-promoting practices. JAN. 2004; 48(4):351-360. [Link]

24. Vameghi M, Sajjadi H, Ghayed Amini Harounii G, Namdari M. Predicting risk taking behavior by exposure to domestic violence among Khorram-abad 
adolescents. Social Welfare. 2017; 17(65):171-197. [Persian]. [Link]

25. Esmaielzadeh H, Asadi M, Miri N, Keramatkar M. Prevalence of high risk behaviors among high school students of Qazvin in 2012. IJE. 2014; 10(3):75-82. [Persian]. [Link]

26. Nolen-Hoeksema S, Morrow J. A prospective study of depression and posttraumatic stress symptoms after a natural disaster: the 1989 Loma Prieta Earthquake. JPSP. 1991; 61(1):115-120. [Link]

27. Ahmadi Bejagh S, Bakhshipour B, Faramarzi M. The effectiveness of group mindfulness - Based cognitive
Therapy on obsessive-compulsive disorder, metacognition beliefs and rumination. CPS. 2015; 5(20):79-109. [Persian]. [Link]

28. Kiyamryy A, Najarian B, Mehrabizade M. Construction and validation of a measure of hardiness. Journal of Psychology. 2004; 1(7):271-284. [Persian]. [Link]

29. Zadeh Mohammadi A, Ahmadabadi Z, Heidari M. Construction and assessment of psychometric features of Iranian adolescents risk-taking scale. IJPCP. 2011; 17(3):218-225. [Persian]. [Link] 